\title{
BibliograPHY
}

1. J. L. Synge and A. Schild, Tensor calculus, 2nd ed., University of Toronto Press, Toronto, 1952, pp. $142-146$

2. G. Ricci and T. Levi-Civita, Methodes de calcul differential absolu et leurs applications, Math. Ann. 54, 125-201 (1901)

3. H. Neuber, Die Grundgleichungen der elastischen Stabilität in allgemeinen Koordinaten und ihre Integration, Z. angew. Math. u. Mech. (6) 23, 321-330 (1943)

4. A. E. Green and W. Zerna, Theoretical elasticity, Oxford at the Clarendon Press, 1954, pp. 18-22, $57-61$

5. C. Truesdell, The physical components of vectors and tensors, Z. angew. Math. u. Mech. (10/11) 33, 345-356 (1953)

6. C. Truesdell, Remarks on the paper, "The physical components of vectors and tensors", Z. angew. Math. u. Mech. (1/2) 34, 69-70 (1954)

\section{A NOTE ON THE DECOMPOSITION OF STRESS AND STRAIN TENSORS*}

\section{BY BERNARD BUDIANSKY AND CARL E. PEARSON (Harvard University)}

A well-known theorem of vector analysis states that an arbitrary vector field can be decomposed into the sum of two fields, one of which is irrotational and the other solenoidal. Analogous theorems for stress and strain tensor fields are presented in this note.

Theorem 1. A symmetrical (stress) tensor $\sigma_{i j}$ defined in the region $V$ bounded by the surface $S$ may be written

$$
\sigma_{i j}=\sigma_{i i}^{\prime}+\sigma_{i j}^{\prime \prime}
$$

where $\sigma_{i j}^{\prime}$ and $\sigma_{i j}^{\prime \prime}$ have the following properties:

(a) $\sigma_{i, i}^{\prime}=-f_{i}^{0} \quad$ in $V$, $\sigma_{i ;}^{\prime} n_{i}=T_{i}^{0} \quad$ on a portion $S_{B}$ of $S$, where $f_{i}^{0}$ and $T_{i}^{0}$ are prescribed ${ }^{1}$, and $n_{i}$ is the unit normal to $S$.

(b) the (strain) tensor $\epsilon_{i i}^{\prime \prime}$ derived from $\sigma_{i i}^{\prime \prime}$ by the Hookean relation

$$
\epsilon_{i j}^{\prime \prime}=L\left(\sigma_{i j}^{\prime \prime}\right)=\frac{1}{E}\left[(1+\nu) \sigma_{i j}^{\prime \prime}-\nu \sigma_{k k}^{\prime \prime} \delta_{i i}\right]
$$

is related to some (displacement) vector field $u_{i}^{\prime \prime}$ by

$$
\epsilon_{i j}^{\prime \prime}=\frac{1}{2}\left(u_{i, j}^{\prime \prime}+u_{i, i}^{\prime \prime}\right) \text {, }
$$

where $u_{i}^{\prime \prime}$ takes on the prescribed value $u_{i}^{0}$ on $S_{A}=S-S_{B}$.

In other words, the theorem states that any stress field can be decomposed into the sum of two fields, one of which obeys prescribed conditions on internal and surface equilibrium and the other of which provides (through Hooke's law) strains that satisfy internal and surface compatibility requirements. The analogy with the corresponding result for vector fields is evident: the equilibrium condition involves the divergence of the stress tensor (a solenoidal vector is divergence-free) and compatibility requires that

*Received December 20, 1955.

${ }^{1}$ Here $f_{j}^{0}$ and $T_{i}^{0}$ have the character of body force and surface traction, so that if $S_{B}$ is the entire surface, they must be so chosen as to satisfy overall static equilibrium. 
strain be derivable from displacement (an irrotational vector is derivable from a potential). ${ }^{2}$

The proof of the theorem rests on the fact that $\sigma_{i}^{\prime \prime}$ may be chosen as the solution to the following mixed houndary value problem for $\sigma_{i j}^{\prime \prime}, u_{i}^{\prime \prime}$, and $\epsilon_{i j}^{\prime \prime}$ :

$$
\begin{aligned}
& \sigma_{i, i}^{\prime \prime}=\sigma_{i i, i}+f_{i}^{0} \quad \text { in } V, \\
& \epsilon_{i i}^{\prime \prime}=L\left(\sigma_{i j}^{\prime \prime}\right)=\frac{1}{2}\left(u_{i, i}^{\prime \prime}+u_{i, i}^{\prime \prime}\right) \quad \text { in } V, \\
& \sigma_{i i}^{\prime \prime} n_{i}=\sigma_{i j} n_{i}-T_{i}^{0} \quad \text { on } S_{B}, \\
& u_{i}^{\prime \prime}=u_{i}^{0} \quad \text { on } S_{A} .
\end{aligned}
$$

Then the choice $\sigma_{i i}^{\prime}=\sigma_{i i}-\sigma_{i j}^{\prime \prime}$ satisfies

$$
\begin{array}{ll}
\sigma_{i, i}^{\prime}=-f_{i}^{0} & \text { in } V, \\
\sigma_{i,}^{\prime} n_{i}=T_{i}^{0} & \text { on } S_{B},
\end{array}
$$

and so $\sigma_{i j}^{\prime}$ and $\sigma_{i j}^{\prime \prime}$ constitute the elements of the required decomposition.

Theorem 2. A symmetrical (strain) tensor $\epsilon_{i j}$ defined in $V$ may be written

$$
\epsilon_{i j}=\epsilon_{i j}^{\prime}+\epsilon_{i j}^{\prime \prime}
$$

where $\epsilon_{i j}^{\prime}$ and $\epsilon_{i j}^{\prime \prime}$ have the properties

(c) $\epsilon_{i j}^{\prime \prime}=\frac{1}{2}\left(u_{i, i}^{\prime \prime}+u_{i, i}^{\prime \prime}\right)$, where $u_{i}^{\prime \prime}$ is a (displacement) vector that takes on the values $u_{i}^{0}$ on $S_{A}$,

(d) the (stress) tensor $\sigma_{i i}^{\prime}=H\left(\epsilon_{i i}^{\prime}\right)$, where $H$ is the inverse of $L$, satisfies

$$
\begin{array}{ll}
\sigma_{i, i}^{\prime}=-f_{i}^{0} & \text { in } V, \\
\sigma_{i j}^{\prime} n_{i}=T_{i}^{0} & \text { on } S_{B} .
\end{array}
$$

This theorem follows immediately from the application of Theorem 1 to the stress tensor $\sigma_{i i}=H\left(\epsilon_{i j}\right)$ with the result that the decomposition $\sigma_{i i}=\sigma_{i i}^{\prime}+\sigma_{i j}^{\prime \prime}$ obeys conditions (a) and (b). Then the strain tensors $\epsilon_{i i}^{\prime}=L\left(\sigma_{i j}^{\prime}\right)$ and $\epsilon_{i i}^{\prime \prime}=L\left(\sigma_{i j}^{\prime \prime}\right)$ provide the elements of the required decomposition of $\epsilon_{i j}$.

'The reader is cautioned not to infer that $\sigma_{i j}^{\prime \prime}$ satisfies the conventional Beltrami-Michell compatibility equations, since these involve equilibrium conditions that $\sigma_{i}^{\prime \prime}$ need not satisfy.

\section{ON VARIATIONAL PRINCIPLES AND GALERKIN'S PROCEDURE FOR NON-LINEAR ELASTICITY*}

BY BERNARD BUDIANSKY AND CARL E. PEARSON (Harvard University)

Variational principles are discussed by Greenberg [1] for the following problem of non-linear elasticity** in the region $V$ bounded by the surface $S=S_{A}+S_{B}$ :

$$
\begin{aligned}
& \sigma_{i i, i}=0 \quad \text { in } V, \\
& \epsilon_{i j}=\frac{1}{2}\left(u_{i, i}+u_{i, i}\right) \quad \text { in } V, \\
& u_{i}=u_{i}^{0} \quad \text { on } S_{A}, \\
& \sigma_{i j} n_{i}=T_{i}^{0} \quad \text { on } S_{B},
\end{aligned}
$$

*Received December 20, 1955.

**The non-linearity is incorporated only in the stress-strain relations; displacements are still assumed small. 